
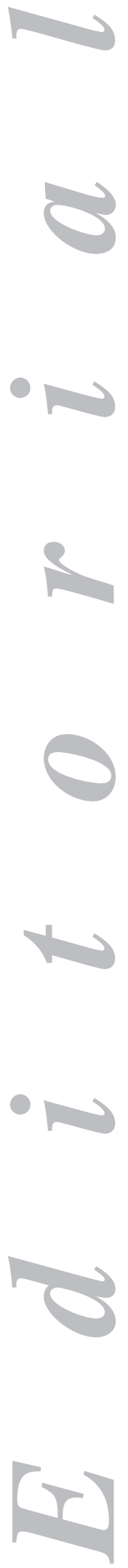

\section{¿Cómo se comporta la hepatitis autoinmune en los niños?}

La hepatitis autoinmune (HAI) es una enfermedad rara en la infancia, pero frecuente si sólo se consideran los niños con hepatopatía crónica (1). La lesión hepática es crónica, progresiva y aunque de etiología desconocida, la patogenia se atribuye a una reacción autoinmune. La historia natural de la enfermedad demuestra su gravedad y mal pronóstico, especialmente en niños, evolucionando a cirrosis e insuficiencia hepática en los pacientes no tratados. Sorprende la escasa casuística publicada sobre el tema en la infancia, por ello la serie de pacientes de García Romero y cols. resulta de gran interés. A pesar de que es un estudio retrospectivo de 7 pacientes, hay que destacar: a) que están bien estudiados; b) que abarca a toda la edad pediátrica (el más pequeño de 21 meses); c) se observa un predominio en las mujeres, que en el caso del tipo II es del 100\%; d) están representadas todas las manifestaciones clínicas descritas en la literatura, hay un caso de diabetes asociada al tipo I y de antecedentes maternos de vitíligo, que es un hallazgo descrito con cierta frecuencia; y por último, e) la forma de presentación del tipo II fue asintomática aunque con elevada cistolisis.

La HAI afecta a ambos géneros y a todas las edades. En niños, la prevalencia del tipo I es del 62-65\%, frente al 35-38\% la del tipo II $(1,2)$; aún así, el tipo II es mucho más frecuente en niños que en adultos, ya que no supera el 3-4\% (1). No obstante, en Francia y Alemania, el 20\% de los adultos con HAI son de tipo II (3). Tiene una especial predilección por el género femenino, que en el tipo II puede llegar al $95 \%$ (4). Clásicamente se consideraba la máxima incidencia de aparición en niños después de los 3 años de vida, pero en algunas series, el 30\% de los niños tenían menos de 3 años (4) y se han descrito casos en niños menores de un año.

La clasificación está basada en el tipo de anticuerpos presentes en el enfermo. Cada autoanticuerpo tiene un antígeno diana, que en el tipo I son los anticuerpos antinucleares (ANA) frente al centrómero, histonas y ribonucleoproteínas, y/o anticuerpos anti-músculo liso (SMA) frente a actina, tubulina y filamentos intermediarios. El tipo II se caracteriza por la positividad de los anticuerpos anti-LKM-1 (antimicrosoma hepatorrenales) frente al antígeno citocromo P450 DB1 (IID6), localizado en el retículo endoplásmico y/o anticuerpos anticitosol hepático tipo 1 (LC1) frente a proteína citosólica hepática. En pacientes adultos se ha definido el tipo III por la presencia de anticuerpos anti-antígeno soluble hepático (SLA) frente a citoqueratinas 8 y 18 y glutatión-S-transferasa y/o anticuerpos antihepatopancreático (LP) frente a proteínas citosólicas, en los niños estos marcadores están presentes también pero asociados al tipo I o II (5). El antirreceptor de la asialoglucoproteína (ASGP-R) frente a glucoproteína transmembranosa, ha sido descrito en los tres tipos de HAI, tanto en adultos como en niños $(6,7)$, aunque en niños está presente con mayor frecuencia en el tipo I. Recientemente se ha descrito en la membrana del 
hepatocito un receptor específico para los antiLKM-1, que demostraría una acción patogénica directa $(8)$.

La HAI es más frecuente en la raza blanca y en la población europea. Los antecedentes familiares se acumulan en la mayoría de los pacientes en asociación con un trasfondo hereditario inmunogenético, relacionado con ciertos antígenos de histocompatibilidad del sistema HLA A1, B8, DR3 y DR4. La HAI tipo I está asociada a HLA DR3 (DRB1*0301) y DR4 (DRB1*0401) en pacientes del norte de Europa y Norte América, y tienen relación con la susceptibilidad a la enfermedad y manifestaciones clínicas $(9,10)$. Los pacientes con DR3 son más jóvenes y responden peor al tratamiento, siendo más frecuente la recidiva de la enfermedad tras la retirada del mismo. En estos casos la posibilidad de trasplante hepático se da con mayor frecuencia que si presentan otros alelos. En cambio, los pacientes con DR4, suelen tener mayor edad, cursan con otras enfermedades autoinmunes y responden mejor a los corticoides (11). La HAI tipo II es más frecuente en Europa y en zonas de América del sur y está asociada a DRB1*0701 (12). En los niños se ha relacionado el tipo I con DRB1* y el tipo II con DQB1 (13).

En la historia clínica hay antecedentes de enfermedades autoinmunes (35-40\%) en los familiares de primer grado como tiroiditis, vitíligo, diabetes juvenil y lupus eritematoso. El propio niño puede presentar alteraciones sistémicas del tipo de hipo o hiperparatiroidismo, anemia hemolítica autoinmune, diabetes insulin-dependiente, glomerulonefritis, displasia vascular multiorgánica, vitíligo e hiperinsulinemia con hipoglucemia. Estas manifestaciones extrahepáticas están presentes hasta en el 60\% de los casos cuando es del tipo II y con menos frecuencia en el tipo I (28\%) (13). Ciertos factores ambientales podrían estar relacionados con el desarrollo de HAI en enfermos genéticamente susceptibles, algunos virus hepatotropos han sido implicados como el herpes tipo 1 y la HAI tipo II, el virus de la hepatitis A con el tipo I y el virus de la hepatitis C con el tipo II (14), entre otros.

La forma de presentación es variada, como una hepatitis aguda ligada a una enfermedad general con cansancio e ictericia; en otras ocasiones, se trata de un hallazgo casual con hepato-esplenomegalia y/o aumento de transaminasas. También se han descrito formas hiperagudas con insuficiencia hepática aguda grave. El tiempo transcurrido entre el primer síntoma y el diagnóstico en pediatría es muy variable, en algunas series entre 1 mes y 7 años. La hepatomegalia suele estar presente en la mayoría de los casos y en una proporción importante sólo el lóbulo izquierdo es palpable. La historia natural de la HAI en niños es más agresiva, y cerca del 50-69\% en el tipo I y $38 \%$ en el tipo II, tienen cirrosis hepática en el momento del diagnóstico (2). Esto puede ser interpretado como una expresividad clínica más larvada o un retraso en el diagnóstico (15). No obstante, la recurrencia de la enfermedad postrasplante ocurre con mayor frecuencia en niños que en adultos y responden peor al tratamiento (16).

Los hallazgos histológicos, aunque poco específicos, muestran una hepatitis de la interfase con infiltrado mononuclear, plasmocitario y formación de rosetas. La histología es importante para conocer la evolución de la lesión hepática, ya que ni las transaminasas ni los niveles de gammaglobulinas orientan hacia la presencia o ausencia de cirrosis hepática. También la histología es interesante para descartar una patología biliar con granulomas o cambios sugerentes de otras enfermedades. En el trabajo de García Romero y cols., publicado en este número de la Revista Española de Enfermedades Digestivas, hay que resaltar la baja incidencia de cirrosis hepática, que indica que el diagnóstico de la enfermedad fue precoz lo que sin duda mejora el pronóstico (17). 
El diagnóstico precoz unido a un tratamiento rápido modifica la historia natural de la enfermedad. En la infancia la HAI es considerada de peor pronóstico que en el adulto, aunque hay autores que se cuestionan este aspecto y piensan que el tiempo transcurrido sin un diagnóstico cierto puede ser excesivo. A favor de la teoría anterior, sólo un paciente de la serie descrita necesitó un trasplante hepático, precisamente aquel que tenía al diagnóstico una cirrosis hepática establecida. El tratamiento de estos enfermos fue la asociación de prednisona y azatioprina, salvo en un caso catalogado como leve que fue tratado con prednisona de forma aislada y respondió correctamente. La remisión se consiguió en la mayoría de los pacientes, aunque en algunos fue necesario un tiempo de hasta 3 años para alcanzar la respuesta bioquímica. De los 7 pacientes, 2 están en remisión con dosis de mantenimiento de azatioprina, y 3 de ellos necesitan también esteroides, siendo la supervivencia del 100\%.

El retraso en el diagnóstico en los niños con respecto al adulto merece algún comentario. Los adultos con frecuencia son sometidos a estudios analíticos, incluyendo la bioquímica hepática, cuando van a donar sangre, en los exámenes de salud de las empresas o ante la sospecha de cualquier enfermedad leve. En cambio, en los niños, salvo casos de enfermedad manifiesta, se es más condescendiente y la indicación de extracción sanguínea se hace con menos frecuencia. Sorprende la poca costumbre que tenían los pediatras para solicitar la ALT y AST cuando un niño precisaba una extracción sanguínea. En la actualidad está cambiando este hecho, y cada vez es más frecuente atender en la consulta de hepatología infantil a niños para estudio por este hallazgo.

El diagnóstico de HAI se debe incluir en todos los niños con aumento de transaminasas, y está basado en las manifestaciones clínicas y en los datos analíticos: aumento de transaminasas con predominio de ALT o con similares valores de AST y ALT, hipergammaglobulinemia ( $\mathrm{IgG}$ ) y la presencia en suero de autoanticuerpos no-órgano específicos. Resulta de interés utilizar la codificación de los criterios diagnósticos usados en adultos, pero con la adaptación a la infancia, por ejemplo para los anti LKM-1 es suficiente títulos de 1/20 (18). También el cociente FA/AST no se debería incluir en el diagnóstico, ya que en los niños la FA está elevada por el crecimiento. El aumento de la GGT puede sugerir colestasis (19). La colangitis esclerosante autoinmune ha sido descrita en niños (20), y puede ser indistinguible de la HAI cuando predomina la colestasis. En estos casos la colangioRMN (21), la CPRE o la colangiografía percutánea, puede ser necesaria para el diagnóstico diferencial de estos procesos.

En todos los pacientes hay que excluir las enfermedades hereditarias como la enfermedad de Wilson, la deficiencia de alfa-1-antitripsina y la hemocromatosis. También hay que investigar la posibilidad de una hepatitis viral, medicamentosa, la obesidad y en los adolescentes las relacionadas con el alcohol. Ante la sospecha de HAI con ANA, SMA o antiLKM1 negativos hay que solicitar otros anticuerpos del tipo ASGPR, LC1, SLA/LP, actina y pANCA, cANCA. Los autoanticuerpos no causan la enfermedad y no reflejan la respuesta al tratamiento; por tanto, no es necesaria su monitorización durante el seguimiento del paciente.

El pronóstico está determinado por la respuesta a los corticoides y por lo evolucionada que esté la lesión en el momento del diagnóstico (22). También puede condicionar el pronóstico la gravedad de las manifestaciones extrahepáticas de autoinmunidad. En los adultos, si las transaminasas no disminuyen al menos un 50\% del valor inicial a los seis meses de instaurado el tratamiento, es necesario pensar en otras estrategias de tratamiento y predice la necesidad de trasplante hepático (23). Una buena respuesta al tratamiento convencional previene la progresión de la enfermedad y su descompensación, el tratamiento con corticoides puede disminuir la fibrosis (24). 
La HAI rara vez remite de forma espontánea, así que el tratamiento se plantea sin demora tras el diagnóstico. Los objetivos del tratamiento son intentar modificar la historia natural de la enfermedad, la progresión hacia la cirrosis y el fallo hepático, la necesidad de trasplante y sobre todo disminuir la mortalidad. En pediatría carecemos de ensayos clínicos controlados, como en la mayoría de las enfermedades pediátricas, así que se adoptan las medidas terapéuticas de los adultos, aunque en este proceso tampoco abundan los ensayos clínicos. Los corticoides han probado su eficacia y es el fármaco de elección. La azatioprina en monoterapia es menos efectiva que la asociación con corticoides y permite usar una menor dosis, lo que reduce sus efectos adversos. Esta combinación es la elección aceptada en la actualidad para la inducción de la remisión. En los niños se recomienda la prednisona a una dosis de $2 \mathrm{mg} / \mathrm{kg} / \mathrm{día}$, sin superar los $60 \mathrm{mg} /$ día, durante al menos dos semanas en monoterapia o en combinación con azatioprina $1-2 \mathrm{mg} / \mathrm{kg} /$ día. Las dosis de mantenimiento para la prednisona es de $0,1-0,2 \mathrm{mg} / \mathrm{kg} /$ día o $5 \mathrm{mg} /$ diarios, la azatioprina se mantiene a la misma dosis. El tratamiento combinado se puede hacer desde el inicio, o bien asociar más tarde la azatioprina a la prednisona para evitar los efectos adversos de este fármaco o porque no se pueda reducir la dosis de esteroides.

La remisión completa no está definida en la población infantil, en adultos se considera remisión a la mejoría de los síntomas, unido a la normalización de las transaminasas, la bilirrubina y las gammaglobulinas en el primer año de tratamiento y mantenida al menos durante seis meses de tratamiento adicional. También se considera un parámetro de respuesta la presencia de una actividad mínima en la biopsia hepática. Este tipo de remisión se consigue, entre uno y tres meses desde el inicio del tratamiento, en el 60-80\% de los pacientes adultos. El tratamiento de mantenimiento está indicado una vez conseguida la remisión para prevenir las recidivas, la azatioprina es el fármaco de elección (25) y con menos efectos adversos, pero la mayoría de las veces hay que mantener dosis pequeñas de corticoides. La decisión de la retirada total de la medicación se puede plantear si se mantiene la remisión bioquímica e histológica con ausencia de actividad inflamatoria en la biopsia hepática después de 2-4 años de tratamiento continuado. La recidiva una vez conseguida la respuesta o simplemente la reaparición grave de los síntomas requiere aumentar o iniciar de nuevo el tratamiento inmunosupresor, y en este supuesto se debe mantener el tratamiento a largo plazo o durante toda la vida. Cualquier disminución de la medicación en la edad pediátrica debe hacerse con lentitud y vigilancia.

Muy pocos pacientes no responden a los corticoides, en otras ocasiones la presencia de efectos adversos aconsejan usar otros fármacos. La budesonida mantiene su potencia antinflamatoria y tiene menos efectos sistémicos que la prednisona, en niños podría ser una buena opción terapéutica, aunque no parece una alternativa eficaz. Otro fármaco es la 6-mercaptopurina si hay intolerancia a la azatioprina. La ciclosporina, aunque puede inducir insuficiencia renal e hipertensión arterial, tiene la ventaja de que se miden sus tasas plasmáticas para controlar los efectos adversos (26). La ciclosporina en monoterapia se ha usado en niños como primera opción terapéutica en un número reducido de pacientes con buenos resultados, y asociada a los esteroides y a la azatioprina en algunos pacientes que recidivaron o no respondieron al tratamiento convencional, aunque después de varios años de tratamiento fue suspendida por efectos adversos en un número no despreciable de pacientes (27). La experiencia con otros fármacos como el FK-506-tacrolimus, micofenolato mofetil, ácido ursodesoxicólico y rapamycin es muy escasa para obtener conclusiones. Por último, el trasplante hepático es la única opción terapéutica para muchos pacientes. Sin embargo, en los niños parece más frecuente la reaparición de la enfermedad en el hígado trasplantado, incluso cumpliendo de 
manera exhaustiva el tratamiento inmunosupresor. También la HAI de novo fue descrita originalmente en niños trasplantados por otra causa distinta, especialmente los que recibían ciclosporina, con posterioridad fue descrita en adultos que recibían también tacrolimus. Este es un hallazgo no demasiado frecuente, pero que condiciona un peor pronóstico y es frecuente el desarrollo de cirrosis hepática en el injerto (28). En los adultos y en niños, al introducir de nuevo los corticoides, se consigue mejorar la supervivencia del injerto y se aconseja su mantenimiento (29).

Un aspecto poco estudiado es cómo viven los niños este proceso, se han comunicado casos de suicidio, y rechazo a la medicación por los cambios en el aspecto físico, especialmente en la fase postrasplante. No es raro que precisen en ciertas etapas apoyo psicológico, por lo que cuando son transferidos para su control a las consultas de hepatología de los adultos se debería especificar estos datos en su historia clínica. Hay que considerar que muchos de ellos fueron trasplantados en la primera infancia $y$, aunque pueden llevar una actividad diaria normalizada, su infancia ha estado llena de intervenciones. Hay que cuidar la calidad de vida y la necesidad de apoyo psicológico con especial interés en la adolescencia. Si de adulto necesitan un retrasplante se deberían considerar todos estos datos clínicos antes de rechazarlos por falta de cumplimiento en el tratamiento o por su comportamiento.

\section{A. Ruiz Extremera y J. Salmerón}

Departamento de Pediatría y Unidad de Aparato Digestivo. Hospital Universitario San Cecilio. Facultad de Medicina. Granada

\section{BIBLIOGRAFÍA}

1. Vajro P, Hadchouel P, Hadchouel M, Bernard O, Alagille D. Incidente of cirrhosis in children with chronic hepatitis. J Pediatr 1990; 117: 392-6.

2. Gregorio GV, Portmann B, Reid F, Donaldson PT, Doherty DG, Mccartney M, et al. Autoimmune hepatitis in childhood. A 20 year survey. Hepatology 1997; 25: 541-7.

3. Homberg JC, Abuaf N, Bernard O, Islam S, Álvarez F, Khalil SH, et al. Chronic active hepatitis associated with antiliver/kidney microsoma antibody tipe 1: a second tipe of "autoimmune" hepatitis. Hepatology 1987; 7: 1333-9.

4. Maggiore G, Bernard O, Homero JC, Hadchouel M, Álvarez F, Hadchouel P, et al. Liver disease associated with anti-liver-kidney microsoma antibody in children. J Pediatr 1986; 108: 399-404.

5. Vitozzi S, Djilali-Saiah I, Lapierre P, Álvarez F. Anti-soluble liver antigen/liver-pancreas (SLA/LP) antibodies in pediatric patients with autoimmune hepatitis autoimmunity. 2002; 35 (8): 485-92.

6. Czaja AJ, Manns MP. The validity and importanc of subtypes in autoimmune hepatitis: Apoint of view. Am J Gastroenterol 1995; 90: 1206-11.

7. Hajoui O, Debray D, Martin S, Álvarez F. Auto-antibodies to the asialoglycoprotein receptor in sera of children with auto-immune hepatitis. Eur J Pediatr 2000; 159: 310-3.

8. Vergani D. LKM antibody: getting in some target practice. Gut 2000; 46: 449-50.

9. Donaldson PT, Doherty DG, Hayllar KM, McFarlane IG, Johnson PJ, Williams R. Susceptibility to autoimmune chronic active hepatitis: human leukocyte antigens DR4 and A1-B8-DR3 are independent risk factors. Hepatology 1991; 13 (4): 701-6.

10. Strettell MD, Donaldson PT, Thomson LJ, Santrach PJ, Moore SB, Czaja AJ, et al. Allelic basis for HLA-encoded susceptibility to type 1 autoimmune hepatitis. Gastroenterology 1997; 112 (6): 2028-35.

11. Czaja AJ, Strettell MD, Thomson LJ, Santrach PJ, Moore SB, Donaldson PT, et al. Associations between alleles of the major histocompatibility complex and type 1 autoimmune hepatitis. Hepatology 1997; 25 (2): $317-23$.

12. Bittencourt PL, Goldberg AC, Cancado EL, Porta G, Carrilho FJ, Farias AQ, et al. Genetic heterogeneity in susceptibility to autoimmune hepatitis types 1 and 2. Am J Gastroenterol 1999; 94 (7): 1906-13.

13. Djilali-Saiah I, Renous R, Caillat-Zucman S, Debray D, Álvarez F. Linkage disequilibrium between HLA class II region and autoimmune hepatitis in pediatric patients. J Hepatol 2004; 40 (6): 904-9.

14. Bortolotti F, Muratori L, Jara P, Hierro L, Verucchi G, Giacchino R, et al. Hepatitis C virus infection associated with liver-kidney microsomal antibody type 1 (LKM1) autoantibodies in children. J Pediatr 2003; 142: $185-90$.

15. Czaja AJ, Freese DK. Diagnosis and treatment of autoimmune hepatitis. Hepatology 2002; 36: 479-97. 
16. Birnbaum AH, Benkov KJ, Pittman NS, McFarlane-Ferreira Y, Rosh JR, et al. Recurrente of autoinmune hepatitis in children alter liver transplantation. J Pediatr Gastroenterol Nutr 1997; 25: 20-5.

17. García Romero R, Martín de Carpi J, Bernal Cuartas C, Pinillos Pisón S, Varea Calderón V. Hepatitis autoinmune en la edad pediátrica. Rev Esp Enferm Dig 2007; 99: 255-8.

18. Álvarez F, Berg PA, Bianchi FB, Bianchi L, Burroughs AK, Cancado EL, et al. International Autoimmune Hepatitis Group Report: review of criteria for diagnosis of autoimmune hepatitis. J Hepatol 1999; 31: 929-38.

19. Ebbeson RL, Schreiber RA. Diagnosing autoimmune hepatitis in children: is the International Autoimmune Hepatitis Group scoring system useful? Clin Gastroenterol Hepatol 2004; 2 (10): 935-40.

20. Gregorio GV, Portmann B, Karani J, Harrison P, Donaldson PT, Vergani D, et al. Autoimmune hepatitis/sclerosing cholangitis overlap síndrome in chidhood: a 16-year prospective study. Hepatology 2001; 33: 544-53.

21. Lee WS, Saw CB, Sarji SA. Autoimmune hepatitis/primary sclerosing cholangitis overlap syndrome in a child: diagnostic usefulness of magnetic resonance cholangiopancreatography. J Paediatr Child Health 2005; 41 (4): 225-7.

22. Czaja AJ. Autoimmune liver disease. Curr Opin Gastroenterol 2006; 22: 234-40.

23. Tan P, Marotta P, Ghent C, Adams P. Early treatment response predicts the need for liver transplantation in autoimmue hepatitis. Liver Int 2005; 25: 728-33.

24. Czaja AJ, Carpenter HA. Decreased fibrosis during corticosteroid therapy of autoimmune hepatitis. J Hepatol 2004; 40: 646-52.

25. Sanjoy Banerjee S, Rahhal R, Bishop WP. Azathioprine monotherapy for maintenance of remission in pediatric patients with autoimmune hepatitis. JPGN 2006: 43: 353-6.

26. Czaja AJ. Drug therapy in the managementof type I autoimmune hepatitis. Drugs 1999: 57: 49-68.

27. Debray D, Maggiore G, Girardot JP, Mallet E, Bernard O. Efficacy of cyclosporin A in chidren with tipe 2 autoimmune hepatitis. J Pediatr 1999: 135: 111-4.

28. Evans HM, Kelly DA, McKiernan PJ, Hubscher S. Progressive histological damage in liver allografts following pediatric liver transplantation. Hepatology 2006; 43 (5): 1109-17.

29. Salcedo M, Vaquero J, Bañares R, Rodríguez-Mahou M, Álvarez E, Vicario JL, et al. Response to steroids in de novo autoimmune hepatitis alter liver transplantation. Hepatology 2002; 35: 349-56. 